\title{
NEW APPROACHES TO BOND BETWEEN BAMBOO AND CONCRETE
}

\author{
Arash Azadeh ${ }^{1, a}$, Hassan Haji Kazemi ${ }^{2, b}$ \\ ${ }^{1}$ M.Sc. in Civil Engineering, Ferdowsi University of Mashhad, Iran \\ ${ }^{2}$ Prof. in Civil Engineering, Ferdowsi University of Mashhad, Iran \\ arashazadeh@yahoo.com, ${ }^{\mathrm{a}} \mathrm{hkazemi@um.ac.ir}$
}

\section{Keywords: Bamboo, Concrete, Bond, Corrugation}

\begin{abstract}
Increasing bond between bamboo and concrete is one of the important concerns in using bamboo as reinforcement. Concrete cover rupture and bond failure between bamboo and concrete could be considered as two important causes of element rupture.

In this paper, bamboo corrugation as a new method has been proposed. Bamboo corrugation is suggested as a mechanism to interlock bamboo and concrete in order to assist the cohesion and skin friction and increase the total bond. Because of remarkable difference between steel shear strength and longitudinal shear strength of bamboo, the interlock mechanism is different. First, the relation between parameters like bamboo longitudinal shear strength, concrete shear strength and the kind of coating or treating of bamboo has been investigated. Then, the proper shape of bamboo corrugation (relation between size, depth and space between dents) will obtain. Using corrugated bamboo strip can improve bond between these two materials even if bamboo strips have not been treated.
\end{abstract}

\section{Introduction}

Substituting steel bars by a composite such as bamboo in concrete structures in recent decades has been the concern of many researchers around the world. Proper use of bamboo as reinforcement in concrete can significantly improve the strength of concrete members.

The present article try to propose some points based on theories and experiments in order to improve the bond between bamboo and concrete. In the literature review, some results have been presented for different types of bamboo strips treatment in pull-out test. Also the role of node in the pull-out test has been presented in one of these tests. When sliding happens, it produces concentrated tensile force that can split the concrete cover by wedging effect mechanism. Then a new method has been introduced to improve interlock between bamboo and concrete. In this simple method the ratio between three main dimensions (length of dent, space between them and depth of notch) based on some mechanical property of bamboo should be determined then for more clarity a numerical sample has been presented.

\section{Literature Review}

Many experiments and investigations have been done about reinforcing concrete by bamboo heretofore. Some of these investigations are related to bond between bamboo and concrete. Pull-out test is a routine and important test to evaluate the bond between bamboo and concrete. The pull-out test has been carried out with different shapes (whole bamboo, bamboo strips with and without node) and with or without treatment. Also the different types of coatings can be used with nail, sand and wire to increment the bond. As they are various then the combinations and results can be numerous. All of these variations can be used with whole bamboo, bamboo strips with node or bamboo strips without node.

Some experiment has been carried out by Arghand [1] from Ferdowsi University of Mashhad (1994). In this research bamboo strips have been treated in 11 different groups and each group has 3 specimens. For different conditions such as being green or dry, having node or without and also without treatment and different types of treatment, the ultimate bond strength varying from 0.24 $M P a$ up to $2.97 M P a$. 
Other investigation in this regard has been done by K. Ghavami [2] from PUC, Rio de Janeiro, Brazil (2005). In this investigation some methods for improving the bond between bamboo and concrete have been proposed. One of the methods for improving the bond between these two materials is using Sikadur 32-Gel. This method can increase the bond between bamboo and concrete up to 5.29 times, pull-out strength varying between $0.52 \mathrm{MPa}$ and $2.75 \mathrm{MPa}$ for treatment with Sikadur 32-Gel.

Sakaray et al. [3] carried out similar pull-out test. Two types of uncoated bamboo and water proofing material coated bamboo (ALGICOAT RC-104) have been used for this test. The results vary between 1.45 to $1.95 \mathrm{MPa}$. Also it has been observed that bond stresses of coated and uncoated bamboo samples are close.

In 2011 N. Plangsriskul and N. Dorsano [4] carried out some other experiments on bond between bamboo and concrete. Two types of bamboo - Dendrocalamus Asper and Bambusa Oldhamii - have been considered as samples for this test. Two types of coating (asphalt emulsion and polydimethylsiloxane "PDMS") were applied and tested along with the control samples, which contained no coatings. The test results indicated that the bonding strength between the bamboo and concrete with the asphalt emulsion coating was the greatest at $2.34 \mathrm{MPa}$. The next strongest was the control sample (no coating) at $2.2 \mathrm{MPa}$, then PDMS resulting in $1.06 \mathrm{MPa}$.

Another important factor is using bamboo splits with or without node in pull-out test. There are two failure modes for the bamboo with and without node during the pull out test [4]. The results of tests by Plangsriskul and Dorsano [4], shows that using the bamboo strips with node in pull-out test, can split the concrete.

The non-prismatic shape of the bamboo splits at node can act as a wedge and produce a concentrated tensile force in nodal area [5]. This force can split concrete cover. General shape of a bamboo split at node is usually as Fig. 1:

Fig. 1 (a) Strip without node (b) Strip with node [5].
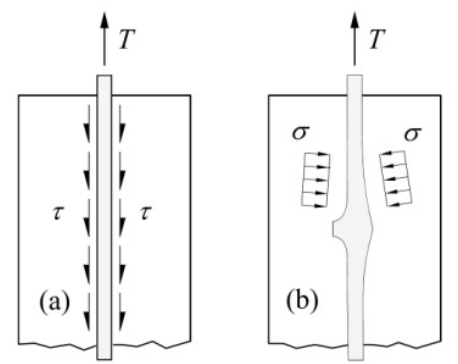

Stress transition between concrete and bamboo in Fig. 1-b is mainly concentrated in nodal zones that could be a weak point for using bamboo strips. These zones are the locations where cracks can be initiated and developed.

For a bamboo strip the distance between two nodes can be divided in 3 zones (not necessarily equal parts): 1 . no-touch zone, 2 . skin friction zone, and 3. wedging action zone.

Fig. 2 Stresses on a bamboo split between two nodes [5].

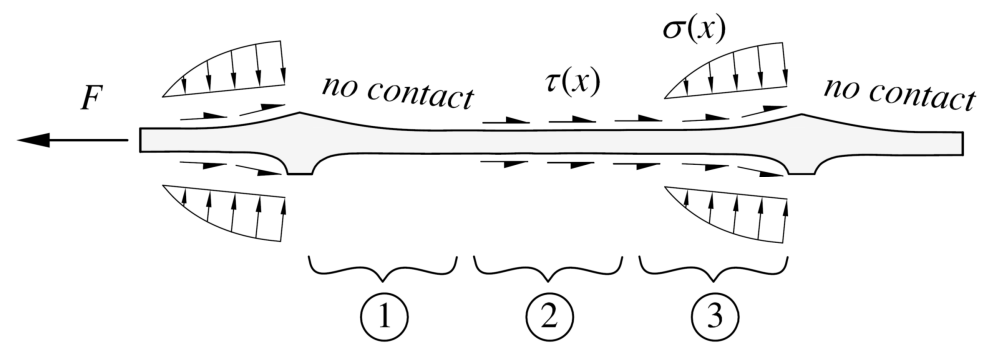




\section{Literature Review Results}

With the same situation, the pull-out test results can be very different. It can happen because of some possible reasons:

1. Using different variety of bamboo: at the same situation, the results show that Bambusa Oldhamii has higher pull out strengths than the Dendrocalamus Asper for all types of coatings [4].

2. Using different type of aggregates for concrete.

3. Using sand for coating with different size and coarseness.

4. Using different amount of cement $\left(f_{c}^{\prime}\right)[1]$.

5. Using different amount of W/C for concrete (different Slump test results).

6. The effect of bamboo Poisson's ratio.

7. Using different shape of concrete molding (cubic or cylinder form) with different dimensions.

8. Using different bamboo strip dimensions (thickness and width).

9. Using different pulling speed.

10. Using bamboo without coating and with different moisture content.

11. Using bamboo splits without parallel faces. The process of making bamboo splits usually produces splits that the cut faces are not parallel together. By making them parallel the pull-out results would be closer to the reality. By using narrow end in concrete the pull-out test result can show less value than expectations but by using thick end in concrete, the bamboo strip can act like a wedge (Fig. 3).

Fig. 3 (a) Recommended. (b) It pulls out with less than usual force. (c) The wedging action and concrete splitting can occur.

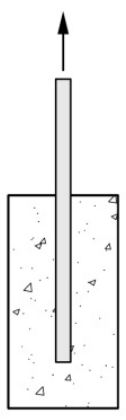

(a)

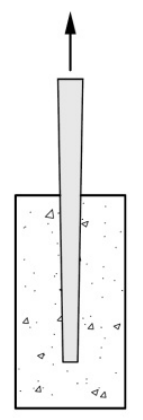

(b)

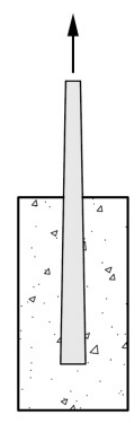

(c)

12. Contrary to expectations, some treatments decrease the bond strength between bamboo and concrete. For example using polydimethylsiloxane (PDMS) coating [4] reduces the bond to1.06 $\mathrm{MPa}$ comparing with 2.2 $\mathrm{MPa}$ for uncoated bamboo.

13. A summary result $[1,2,3,4]$ for bond between bamboo and concrete in three different treatment methods including: without treatment, coated and coated + sand is presented in Fig. 4. It is observed that using sand and coating as treatment can increase the bond between bamboo and concrete about two times:

Fig. 4 Bond strength for three types of treatment.

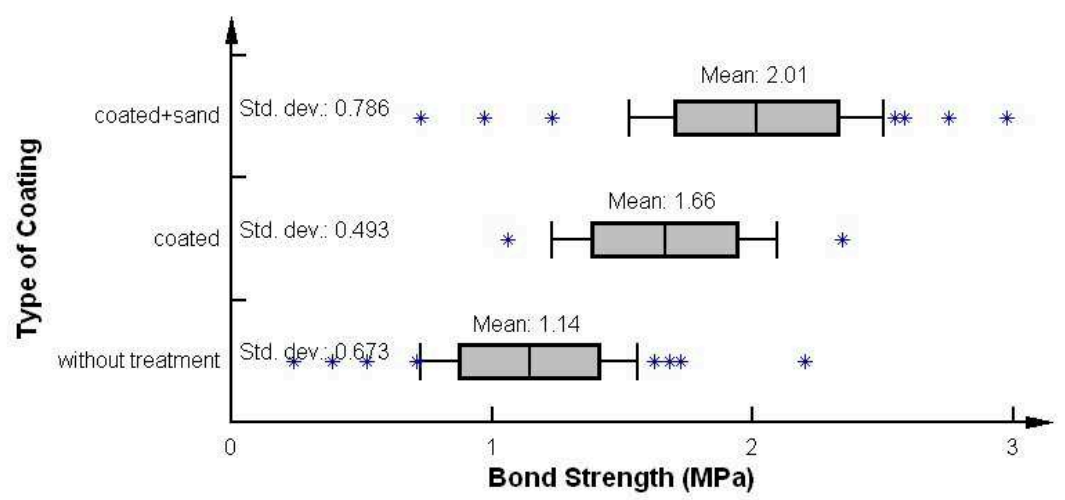

14. As it can be observed from Fig. 2, most of tensile force (F) can be concentrated in frontal faces of node (zone 3). Concrete cover splitting cracks can be easily initiated in this zone. For distributing the concentrated stress $\sigma(x)$, bamboo corrugation can be a proper solution. 


\section{Proposed Method for Bond Improvement \\ 3.1 Introduction}

Like using deformed steel bar as reinforcement, corrugation of bamboo can improve the bond between bamboo and concrete. Also bamboo corrugation can diminish the destructive effect of shrinkage, thermal expansion and wedging effect in untreated bamboo strips.

Although, using proper coating as interface between bamboo and concrete (in addition to water proofing) at some cases can provide adequate skin friction, its value is much less than the bamboo longitudinal shear strength (7.45 MPa for dry and 4.12 $\mathrm{MPa}$ for wet bamboo [5] versus treated bamboo bond strength). The longitudinal shear strength of bamboo is more determinative when the interlock mechanism between bamboo and concrete is important.

Because of some similarities between concrete reinforced by steel bars and concrete reinforced by bamboo strips, the same shapes and equations can be considered. The simplest model representing the stress transfer between a plain bar (bamboo, steel or any other composite) and concrete is frictional model that can be shown as Fig. 5:

Fig. 5 Frictional model [6].

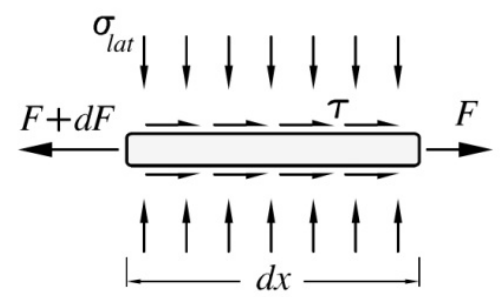

In Fig. 5, the relation between parameters is simple:

$$
\begin{gathered}
d F=\tau . \pi \cdot D_{b} \cdot d x \\
\tau=\left(\mu . \sigma_{\text {lat }}+C\right) .
\end{gathered}
$$

$D_{b}:$ bar diameter

$\mu$ : friction coefficient

$\sigma_{\text {lat }}:$ lateral compression exerted by concrete cover to bamboo strip

$C$ : adhesion

In this type of reinforcement, the skin friction directly depends on lateral compression exerted by concrete cover to bamboo strip and friction coefficient.

The theory of interlocking between deformed bar and concrete is different from using a prismatic and plain bar (Fig. 6).

Fig. 6 Bond force transfer mechanism in a deformed bar [7].

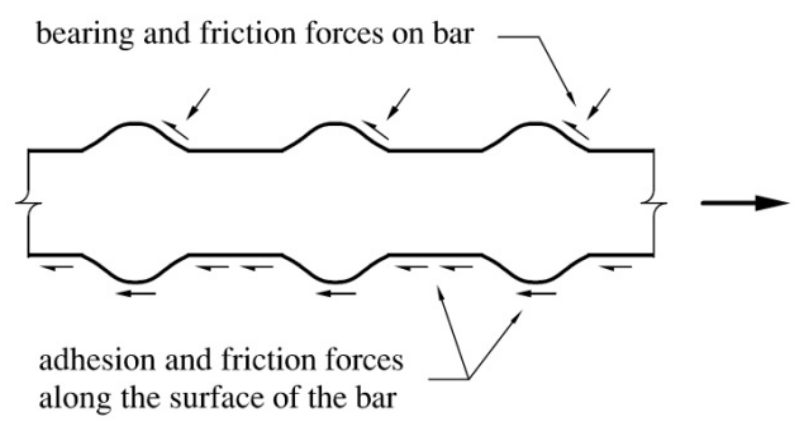

In this mechanism, the failure surface would be a cone that is initiated from dents and the base of cone is towards the tensile force [8]. Due to remarkable difference between steel shear strength and longitudinal shear strength of bamboo (7.45 $\mathrm{MPa}$ for dry and 4.12 $\mathrm{MPa}$ for wet bamboo [5]), all of assumptions and calculations are different. In a steel deformed bar, the base of the dent $(b)$ regarding to distance between dents (c) is small (Fig. 7-1). It can be justified because of difference between steel and concrete shear strength. 
Fig. 7 (1) Typical shape of a steel deformed bar (2) Bamboo corrugated strip.

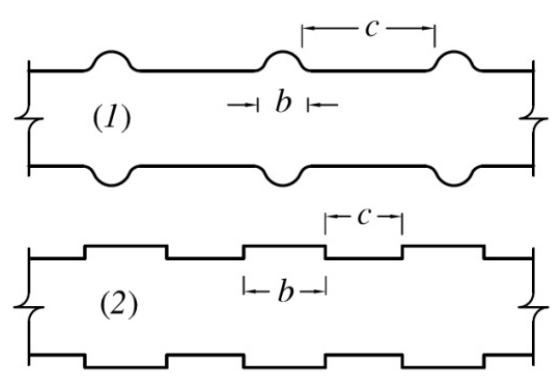

As the bamboo longitudinal shear strength and concrete shear strength are close then the length of dent $(b)$ would be closer to distance between dents $(c)$ :

Because of proper bamboo workability, it can be easily filed and corrugated in field. By using this method for improving the bond, the necessity of using chemical coating for increasing the bond will be lessened.

\subsection{Theory}

Three main factors can justify the corrugation of bamboo strips. There are: 1 . high capacity of bamboo compression strength, 2. adequate longitudinal shear strength of bamboo beside skin friction or adhesion, and 3. proper shear resistance of concrete.

Some typical shapes of bamboo corrugation could be presented as below (Fig. 8):

Fig. 8 Some typical shapes of bamboo corrugation.
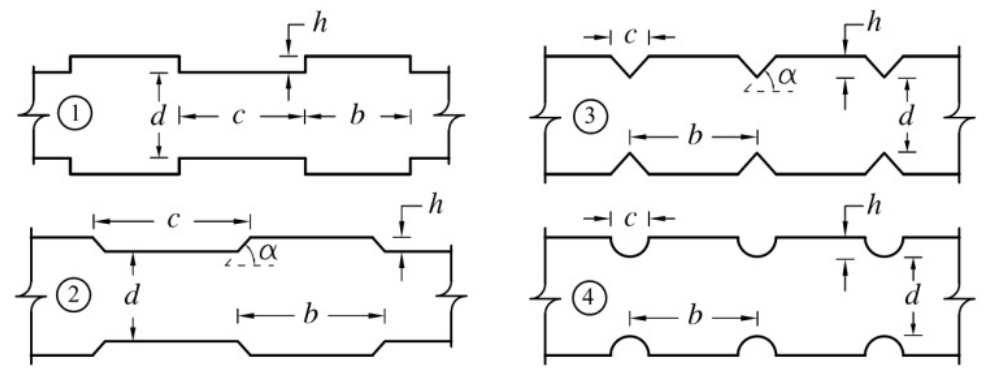

The first one in Fig. 8 can be chosen as the simplest shape for modeling. It is important to find the relations between $b, c$ and $h$. Two independent equations can relate these three geometrical parameters $(b, c$ and $h)$. Then by defining one of them, the two others can be achievable. For this purpose the equilibrium equations shall be extracted from Fig. 9:

Fig. 9 Skin friction, shear and compression on a corrugated bamboo split.

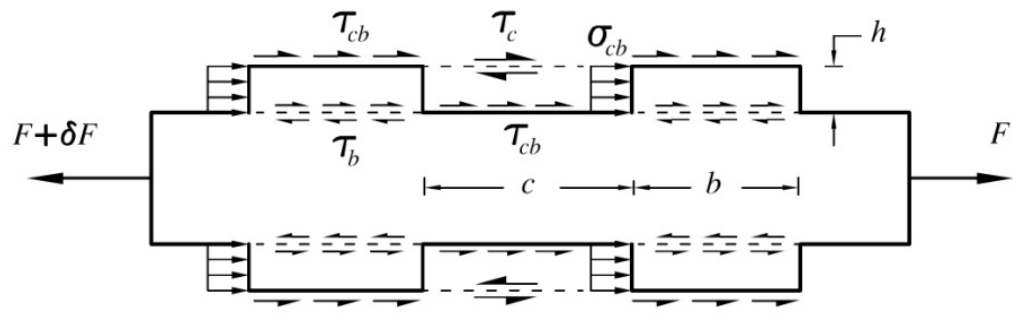

$\tau_{c b}:$ Skin friction between bamboo and concrete

$\tau_{b}$ : Bamboo longitudinal shear tension

$\tau_{c}$ : Concrete shear tension

$\sigma_{c b}$ : Compression between bamboo and concrete

Relation between $b$ and $c$ : in order to find relation between these parameters at first a diagram only for one period of denting (containing a bamboo dent and one distance between two dents) should be extracted from Fig. 9: 
Fig. 10 Tensions in one period of corrugation.

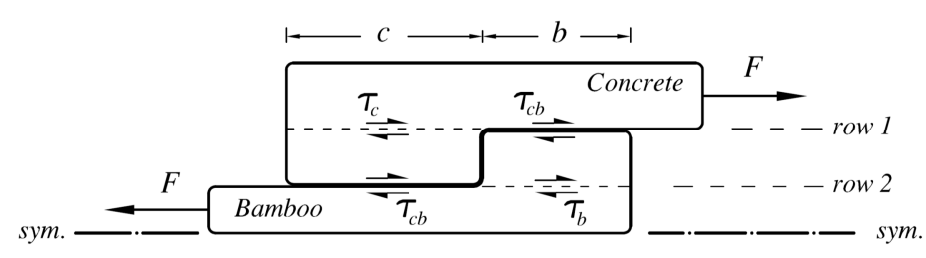

Skin friction plus shear in each material in row 1 and row 2 in Fig. 10 should be the same (these are valid only when $\tau_{c b}<\tau_{b}$ and $\tau_{c b}<\tau_{c}$ ):

$$
\tau_{b} \times b+\tau_{c b} \times c=\tau_{c} \times c+\tau_{c b} \times b \rightarrow \frac{b}{c}=\frac{\tau_{c}-\tau_{c b}}{\tau_{b}-\tau_{c b}} .
$$

Relation between $h$ and $b$ (or $c$ ): For the bamboo element between row 1 and 2 in Fig. 10, the equilibrium equation would be as below (the same diagram and equation can be drafted and written for concrete element):

Fig. 11 Bamboo element (dent) between row 1 and 2.



$$
\frac{h}{b}=\frac{\left(\tau_{b}-\tau_{c b}\right)}{\sigma_{c b}} \text { or } \frac{h}{c}=\frac{\left(\tau_{c}-\tau_{c b}\right)}{\sigma_{c b}} \text {. }
$$

These two equations (Eq. ( $2 \&$ (3) can define relation between $b, c$ and $h$. by assuming one of these parameters, two others can be calculated easily. For $\sigma_{c b}$, the minimum value among ultimate bamboo compression stress $\left(\sigma_{b}\right)$ and ultimate concrete compression stress $\left(\sigma_{c}\right)$ should be considered.

$$
\sigma_{c b}=\min \left(\sigma_{c}, \sigma_{b}\right)
$$

Then the proportional relation between $b, c$ and $h$ can be written as below:

$$
h: b: c=h: \frac{\sigma_{c b}}{\left(\tau_{b}-\tau_{c b}\right)} h: \frac{\sigma_{c b}}{\left(\tau_{c}-\tau_{c b}\right)} h .
$$

The percentage of bond increment due to corrugation: In this section the amount of bond increment for untreated and different types of treatment due to corrugation are investigated. If the section area of bamboo strip is considered as a rectangular, then for each side and for one period of corrugation, $\tau_{\text {ave }}$ can be calculated as below:

$$
\tau_{\text {ave }}=\frac{\tau_{b} \tau_{c}-\tau_{c b}{ }^{2}}{\tau_{b}+\tau_{c}-2 \tau_{c b}} .
$$

As the corrugation is done for two opposite sides then total average bonding stress for two sides $\left(\tau_{\text {tot(2) }}\right)$ would be:

$$
\tau_{\text {tot }(2)}=\frac{\tau_{\text {ave }}+\tau_{c b}}{2}
$$


Generally for $n$ sides corrugation (up to maximum 4 sides) the total average bonding stress $\left(\tau_{\text {tot }(n)}\right)$ will be calculated as below:

$$
\tau_{t o t(n)}=\frac{n \tau_{a v e}+(4-n) \tau_{c b}}{4}
$$

Then the percentage of bond stress increment $(\alpha)$ for $n$ sides is:

$$
\alpha \%=\frac{\tau_{t o t(n)}-\tau_{c b}}{\tau_{c b}} \times 100
$$

\subsection{Practical Example}

As a practical example, the numerical values of some parameters like $\sigma_{c b}, \sigma_{c}, \sigma_{b}, \tau_{b}, \tau_{c}$ and $\tau_{c b}$ that have been defined already, will be used here then the relation between these three parameters can be obtained.

Concrete compressive stress $\left(\sigma_{c}\right)$ can be considered as $f_{c}^{\prime}$ and for this example at mid range it has been taken as $21 \mathrm{MPa}$. But bamboo compressive stress $\left(\sigma_{b}\right)$ can be too variable and depends on different varieties of bamboo and different moisture content (wet or dry). The compression stress that has been measured by Godbole et al. [9] from department of aeronautical engineering, Indian institute of technology (1986), has been reported to be $63.2 \mathrm{MPa}$ for dry bamboo splits and 34.3 $M P a$ for bamboo splits soaked in distilled water for $144 \mathrm{hr}$.

Then:

$$
\sigma_{c b}=\min \left(\sigma_{c}, \sigma_{b}\right)=f_{c}^{\prime}=21 M P a
$$

(Note: as $\sigma_{c}$ is always less than $\sigma_{b}$ in both dry and water saturated condition, then in this conditional equation $\sigma_{c b}=f_{c}^{\prime}$ has been selected.)

For wet and dry bamboo longitudinal shear strength [5]:

$$
\tau_{b}=\left\{\begin{array}{l}
4.12 \mathrm{MPa} \text { for wet bamboo } \\
7.45 \mathrm{MPa} \text { for dry bamboo }
\end{array}\right.
$$

The behavior of concrete between dents as a shear element is complicated. Finding the exact value for concrete shear strength in this special case needs more investigation. Concrete tensile stress is about 10 to 15 percent of the compressive strength [10] or can be $\sqrt{f_{c}^{\prime}} / 1.8$ [11]. By a Mohr's Circle analysis based on tensile and compressive strength of concrete, the shear strength of concrete can be indicated about $0.74\left(f_{c}^{\prime}\right)^{0.75}$. By considering $f_{c}^{\prime}=21 \mathrm{MPa}$, shear strength would be about 7.3 MPa.

$$
\tau_{c}=0.74\left(f_{c}^{\prime}\right)^{3 / 4}=7.3 \mathrm{MPa}
$$

The value for $\tau_{c b}$ or adhesion shear tension between bamboo and concrete, can be extracted from literature review section.

It should be noted that the restrictive factor in this regard is the depth of corrugation $(h)$. The worst case is related to using untreated water saturated bamboo split. Maximum tangential strain is equal to 0.048 [5]. Then by using a $4 \mathrm{Cm}$ width bamboo split, maximum shrinkage in tangential direction will be equal to:

$$
\delta_{\text {tang. }}=40 \mathrm{~mm} \times 0.048=1.92 \mathrm{~mm} .
$$


Thus, the notch depth should be more than $2 \mathrm{~mm}$. On the other hand, by increasing the depth of notch, the remaining depth will be decreased and the result would be the decrement of effective tensile area. By considering the above mentioned factor and depth of notch for each side about 5\% of width of bamboo and assuming $4 \mathrm{Cm}$ for width of bamboo strip, $2 \mathrm{~mm}$ at each side could be proposed as the optimum depth of notch or $h$

Eventually for untreated and water saturated bamboo, the proportional relation between $b, c$ and $h$ by using equation (5) and $\mathrm{h}=2 \mathrm{~mm}$ will be calculated as below (for example $\tau_{c b}=0.52 \mathrm{MPa}$ has been considered for untreated bamboo):

$$
h: b: c=2: \frac{21}{4.12-0.52} \times 2: \frac{21}{7.3-0.52} \times 2=2: 12: 6 .
$$

In this case, $\tau_{\text {ave }}$ and $\alpha$ can be calculated by using Eq. (6) to (9) only for one face:

$$
\tau_{\text {ave }}=2.87 \rightarrow \alpha=450 \% \text {. }
$$

A table for other treating methods with or without considering skin fiction has been prepared $\left(\tau_{c}=7.3 M P a\right.$ and $\left.\sigma_{c b}=21 M P a\right)$ :

\begin{tabular}{|c|c|c|c|c|c|c|c|}
\hline Case & $\begin{array}{c}\tau_{b} \\
(M P a)\end{array}$ & $\begin{array}{c}\tau_{c b} \\
(M P a)\end{array}$ & $\begin{array}{r}\tau_{a v e} \\
(M P a)\end{array}$ & $\begin{array}{r}\alpha \\
\%\end{array}$ & $\begin{array}{c}h \\
(\mathrm{~mm})\end{array}$ & $\begin{array}{c}b \\
(\mathrm{~mm})\end{array}$ & $\begin{array}{c}c \\
(\mathrm{~mm})\end{array}$ \\
\hline $\begin{array}{l}\text { 1. wet bamboo without } \\
\text { treatment }\end{array}$ & 4.12 & 0.52 & 2.87 & 450 & 2 & 12 & 6 \\
\hline $\begin{array}{l}\text { 2. wet bamboo without } \\
\text { treatment (skin friction } \\
\text { ignored) }\end{array}$ & 4.12 & 0 & 2.63 & - & 2 & 10 & 6 \\
\hline $\begin{array}{l}\text { 3. bamboo treated with } \\
\text { negrolin }+ \text { sand }\end{array}$ & 7.85 & 0.73 & 4.15 & 470 & 2 & 6 & 6 \\
\hline $\begin{array}{l}\text { 4. bamboo treated with } \\
\text { negrolin }+ \text { sand (skin } \\
\text { friction ignored) }\end{array}$ & 7.85 & 0 & 3.78 & - & 2 & 5 & 6 \\
\hline $\begin{array}{l}\text { 5. bamboo treated with } \\
\text { negrolin }+ \text { sand }+ \text { wire }\end{array}$ & 7.85 & 0.97 & 4.27 & 340 & 2 & 6 & 7 \\
\hline $\begin{array}{l}\text { 6. bamboo treated with } \\
\text { negrolin }+ \text { sand }+ \text { wire } \\
\text { (skin friction ignored) }\end{array}$ & 7.85 & 0 & 3.78 & - & 2 & 5 & 6 \\
\hline $\begin{array}{l}\text { 7. bamboo treated with } \\
\text { Sikadur 32-Gel }\end{array}$ & 7.85 & 2.75 & 5.15 & 87 & 2 & 8 & 9 \\
\hline
\end{tabular}

Table 1 The increment percentage of skin friction and related corrugating dimensions

\section{Conclusion}

The main results of the current investigation are listed below:

1. The first and the most important advantage of corrugation is the increment of bond between bamboo and concrete.

2. Bamboo corrugation provides uniform distribution of transferring load between bamboo and concrete.

3. Using corrugated bamboo strips can be practicable for temporary structures with using it in the mortar or concrete without any special coating and extra costs.

4. Corrugation can reduce the wedging effect because of changing the stress transition mechanism between bamboo and concrete. 


\section{References}

[1] M.A. Arghand, Concrete reinforcement by bamboo, M.Sc. thesis, Ferdowsi University of Mashhad, 1994.

[2] K. Ghavami, Bamboo as reinforcement in structural concrete elements, Cement \& Concrete Composites 27, 637-649, 2005.

[3] H. Sakaray, N.V. Vamsi Krishna Togati, I.V. Ramana Reddy, Investigation on properties of bamboo as reinforcing material in concrete, International Journal of Engineering Research and Applications (IJERA), Vol. 2, Issue 1, Jan-Feb 2012, pp.077-083.

[4] N. Plangsriskul, N. Dorsano, Materials Characterization of bamboo and analysis of bonding strength and internal strength as a structural member in reinforced concrete, California Polytechnical State University San Luis Obispo, Materials Engineering, Senior Project, 2010-2011.

[5] A. Azadeh, Experimental and theoretical investigation of bamboo \& concrete interaction, M.Sc. thesis, Ferdowsi University of Mashhad, 1999.

[6] S.P. Tastani, S.J. Pantazopoulou, Experimental evaluation of the direct tension -pullout bond test, Bond in concrete from research to standards, Budapest, Hungary, 2002.

[7] ACI Committee 408R (2003), Bond and development of straight reinforcing bars in tension, Journal of the American Concrete Institute.

[8] K. Maekawa, A. Pimanmas, H. Okamura, Nonlinear Mechanics of Reinforced Concrete, Spon Press, 2003.

[9] V.S. Godbole, S.C. Lakkad, Effect of water absorption on the mechanical properties of bamboo, Journal of Materials Science Letters 5, 303- 304,1986.

[10] ACI Committee 318 (2005), Building Code Requirements for Structural Concrete and Commentary, ACI 318M-05, R10.2.5.

[11] ACI Committee 318 (2005), Building Code Requirements for Structural Concrete and Commentary, ACI 318M-05, R11.2.1.1. 